\title{
Reflexões sobre a adaptação como fenômeno ubíquo: o filme $V$ de Vingança
}

\section{Denise Azevedo Duarte Guimarães*}

\section{Resumo}

Este artigo analisa o filme $V$ for Vendetta (2006), dirigido por James Mc Teigue - uma adaptação da graphic novel de Alan Moore e David Lloyde (1988-89). O objetivo é enfatizar a dinâmica do processo tradutório e também problematizar conflitos e/ou soluções criativas nas negociações entre os dois suportes. Esta análise usa o método comparativo baseado na semiótica de Charles Sanders Peirce e em outros teóricos da adaptação, como Robert Stam, Linda Hutcheon, Umberto Eco e Júlio Plaza. São utilizadas ainda teorias sobre quadrinhos e cinema, tentando mostrar como as imagens impressas são dispostas na tela. Conclui-se que a obra analisada conseguiu integrar as exigências intersemióticas concernentes a uma adaptação fílmica bem sucedida.

Palavras chave: Cinema. Graphic Novel. Intersemiose. Teorias da Adaptação.

\section{Reflections on adaptation as an ubiquous phenomenon: the movie $V$ for Venedetta}

\section{Abstract}

The article analyzes the movie $V$ for Vendetta (2006), directed by James Mc Teigue - an adaptation of Alan Moore and David Lloyde's graphic novel (1988-89). The objective is to emphasize the dynamic of the translating process and also to discuss conflicts and/or creative solutions in the negotiations between the two media. This analysis uses the comparative method based on Charles Sanders Peirce's semiotics and on other theorists of adaptation, as Robert Stam, Linda Hutcheon, Umberto Eco and Júlio Plaza. It also uses the comics and cinema theories, trying to show how the printed images are displayed on the screen. The conclusion is that the analyzed film was able to integrate the intersemiotic requirements pertaining to a well done movie adaptation.

Key words: Cinema. Graphic Novel. Intersemiosis. Theory of Adaptation.

* Doutora em Estudos Literários pela UFPR e professora aposentada pela mesma IES. Docente do Programa de Mestrado e Doutorado em Comunicação e Linguagens, Departamento de Comunicação, Universidade Tuiuti do Paraná (UTP). Tem mais de cem artigos publicados em periódicos e anais de congressos. Autora do livro Comunicação tecnoestética nas mídias audiovisuais. Porto Alegre: Sulina, 2007. Docente-fundadora (1997-2009) e vice-coordenadora da Pós-Graduação em Cinema da UTP. Líder do Grupo de Pesquisa Comunicação, Imagem e Contemporaneidade (CNPq).Curitiba-PR, Brasil.E-mail: denise.guimaraes@utp.br 


\section{Reflexiones sobre la adaptación como fenómeno ubíquo: la película $V$ for Venedetta}

\section{Resumen}

El artículo analiza la película $V$ for Vendetta (2006), dirigida por James Mc Teigue - una adaptación de la narrativa gráfica de Alan Moore y David Lloyde (1988-89). El objectivo es enfatizar la dinámica del proceso tradutório y también debatir los conflictos y/o soluciones creativas en las negociaciones entre los dos soportes.La análisis utiliza el método comparativo basado en la semiótica de Charles Sanders Peirce y en otros teóricos de la adaptación, cómo Robert Stam, Linda Hutcheon, Umberto Eco y Júlio Plaza. También se utilizan las teorías de los cómics e del cine, intentando demostrar cómo las imágenes impresas se arreglan en la pantalla.Se concluye que la película logró integrar los requisitos intersemióticos relativos a una exitosa adaptación para el cine.

Palabras clave: Cinema. Graphic Novel. Intersemiose. Teorías de la Adaptación.

\section{Introdução}

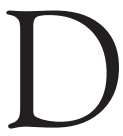

iante das inúmeras narrativas de herois e superherois, que saltam das páginas para as telas, com uma desenvoltura quase mágica e arrebanham uma multidão de espectadores para as salas de cinema, evidencia-se como a linguagem sensorialmente rica e híbrida do cinema contemporâneo acolhe vasto leque de propostas atraentes para a área da Comunicação. $\bigcirc$ fenômeno pode ser ponto de partida e de referência para o estudo de outros produtos e de interfaces midiáticas, o que justifica a escolha do objeto empírico deste artigo: uma análise da adaptação fílmica $V$ for Vendetta (EUA/Alemanha, 2006) ${ }^{1}$. Dirigido por James Mc Teigue, com roteiro dos irmãos Wachowski e a mesma equipe que criou a trilogia Matrix, o filme tem como texto-fonte a graphic novel homônima, de Alan Moore e David Lloyde, publicado em fascículos entre 1988 e 1989, com a edição completa em 1990.

O problema desta pesquisa diz respeito à indagação sobre os modos como o produto cinematográfico em questão mantém,

\footnotetext{
${ }^{1}$ Ficha técnica - V de Vingança. Título Original: V for Vendetta, 2006 (Reino Unido / Alemanha). Direção: James McTeigue. Roteiro: irmãos Wachowski. Atores: Natalie Portman, Hugo Weaving, Stephen Rea, John Hurt, Roger Allam. Duração: 132 min.
} 
manipula ou reformula elementos essenciais da narrativa gráfica original, tendo em vista os conflitos tecnoestéticos das negociações entre os dois suportes, por força das especificidades inerentes a cada um deles.

Nossa hipótese é que, nas produções culturais da atualidade, as narrativas midiáticas, dentre as quais se inclui o cinema, não devem ser entendidas meramente como atividades que atendem aos apelos massivos e reiteram estereotipias, mas também como possíveis reconfiguradoras do imaginário contemporâneo. Nesse sentido, são consideradas as possibilidades de ampliação qualitativa do repertório de uma faixa de público mais afeto a narrativas de ação repletas de efeitos especiais, diante de uma narrativa como $V$ de Vingança, com sua temática adulta e complexa.

São objetivos deste artigo: a) enfatizar a dinâmica do processo tradutório do material impresso para o cinema; b) elencar potencialidades dos elementos expressivos inerentes a cada uma das mídias envolvidas; c) apontar possíveis dificuldades e/ou soluções criativas, para investigar em que medida a estrutura narrativa do texto original é preservada, tanto no que tange ao conteúdo quanto aos aspectos formais.

Nossa opção é o método comparatista, para análise e interpretação do corpus empírico selecionado, com o aporte na semiótica de Charles Sanders Peirce e de teóricos das adaptações, como Robert Stam, Linda Hutcheon, Umberto Eco e Júlio Plaza. São abordadas ainda teorias sobre quadrinhos e cinema, tentando mostrar como a narrativa ficcional e as imagens impressas são re/ apresentadas na tela.

Deixando de lado aferições de valor, como "o original é melhor que o filme" ou vice-versa; a conclusão deste artigo encaminha-se para afirmar que a obra analisada conseguiu contemplar adequadamente as especificidades e sutilezas intersemióticas concernentes a uma adaptação cinematográfica bem sucedida, pois foi mantido o tom fortemente político, erudito e intimista da narrativa de Alan Moore.

\section{Subsídios teóricos}

De início, faz-se mister apontar que, nas últimas décadas do 
século 20, as histórias em quadrinhos passaram a receber olhares atentos de estudiosos, não mais interessados em pensá-las como mero entretenimento ou em investigar seus valores pedagógicos, como era usual, mas sim como produtos da indústria cultural fortemente enraizados na cultura popular. Assim também, a pesquisa empírica na área da Comunicação passou a observá-las como objeto digno de nota, graças ao seu processo em contínuo desenvolvimento, com uma diversidade de gêneros, estilos, materiais e técnicas, e, mais ainda, pelas estéticas e posturas filosóficas que lhes servem de base.

Discussões ambientadas no contexto contemporâneo, no qual avulta uma indústria das HQs expandida e múltipla, avançam em direção a sua função como produto cultural, em constante interface com as outras mídias. Cada produto aponta para a notoriedade de outros com os quais dialoga e vice-versa, de modo que as interações recíprocas funcionam de maneira sinérgica. Poder-se-ia falar no fenômeno da ubiquidade como uma das marcas desta sinergia pós-moderna, entendida por Linda Hutcheon como uma dialética entre o contexto social em constante metamorfose e novas possibilidades de produções artísticas.

Cada vez mais, as HQs dão origem a filmes destinados a um público mais maduro, com temáticas mais complexas e com seus heróis ambíguos ou seus antiherois, apresentados como seres problemáticos que escapam de qualquer postulado maniqueísta.

Mesmo neste contexto, ainda bastante negligenciadas no seio dos estudos sobre cinema, as versões fílmicas de narrativas gráficas estão a merecer maior atenção por parte da academia. Todavia, parece-me que a questão deriva do fato de a investigação dos processos de adaptação, mesmo aquelas que sejam de obras literárias consagradas, terem sido consideradas por muito tempo como algo tangencial à analise de filmes em si. Não parece ter havido, portanto, a devida convicção e o rigor teórico necessários ao seu desenvolvimento como atividade intermidiática. Da mesma forma, apenas recentemente, as teorias da adaptação vêm sendo entendidas como uma promessa capaz de preencher as lacunas metodológicas, no âmbito do diálogo entre narrativas em diferentes suportes, o que é relevante na era da chamada 
convergência das mídias.

Em obra recente, Linda Hutcheon (2006) questiona primeiramente sobre como deve o estudioso posicionar-se face à ubiquidade do fenômeno "adaptação", em suas duas distintas, embora conexas, instâncias. Para a autora, uma adaptação é simultaneamente um produto e uma produção. No primeiro caso, trata-se de uma entidade formal, da mesma natureza dos palimpsestos, conforme estudada por Gérard Genette, ou seja, uma transposição extensiva de obra anterior. Já como produção, é algo que opera um processo específico de leitura e interpretação, sendo, portanto, uma recriação do texto de origem.

Na mesma linha de raciocínio, Umberto Eco afirma que, na adaptação, o comportamento crítico do tradutor torna-se preponderante, "constituindo o próprio cerne da operação de transmutação." Para o teórico italiano, a "adaptação constitui sempre uma tomada de posição crítica - mesmo que inconsciente, mesmo que devida a uma imperícia e não a uma escolha interpretativa consciente (ECO, 2007, p.394-395).

A partir do momento que começaram a ser consideradas como uma forma de tradução, as adaptações passaram a merecer a atenção de estudiosos do cinema, como por exemplo, Robert Stam. O autor explica que a teoria da tradução dispõe de um rico universo de termos e tropos que permitem diferentes dimensões para o conceito de adaptação e cita, dentre eles: transmutação, transfiguração, transmogrificação, transcodificação, reescrita e leitura. O principal é que Stam delineia seu entendimento sobre algumas categorias cruciais para as operações tradutórias, além de efetuar uma crítica ao conceito da fidelidade como princípio metodológico. Diz o autor (2008, p.22):

ainda podemos falar de adaptações bem sucedidas ou não, mas agora orientados não por noções rudimentares de "fidelidade", e sim pela atenção dada a respostas dialógicas específicas, a "leituras", "críticas", "interpretações" e reescritas" de romances-fonte, em análises que invariavelmente levam em consideração as inevitáveis lacunas e transformações na passagem para mídias e materiais de expressão muito diferentes.

autor aponta os conceitos do dialogismo (Mikail Bakhtin) 
e de intertextualidade (Júlia Kristeva) como uma possibilidade de transcender as aporias da "fidelidade". Ele explica que Gérard Genette, com base nos autores citados, "propõe o termo transtextualidade, mais abrangente,” (STAM, 2008, p.21) conceito operatório que lhe parece ser o mais produtivo em termos de adaptação.

Por sua vez, Claus Clüver (1997, p.43), estudioso dos diálogos entre as artes e que vem construindo uma base teórica significativa sobre as intermidialidades contemporâneas, entende que,

(...) o conceito de "tradução intersemiótica" soa melhor se restringido a textos (em qualquer sistema sígnico) que, em primeiro lugar, oferecem uma reapresentação relativamente ampla (mesmo que jamais completa) do texto-fonte composto num sistema sígnico diferente, numa forma apropriada, transmitindo certo sentido de estilo e técnica e incluindo equivalentes de figuras retóricas; e, em segundo lugar, acrescentem relativamente poucos elementos, sem paralelo no texto-fonte.

Para o autor, ler um texto como tradução de outro implica perceber uma exploração de substituições e semiequivalências, de possibilidades e limitações; e ele acrescenta que as reações dos leitores podem ser tanto de fascínio diante das soluções encontradas, quanto de constatação das diferenças essenciais entre os sistemas sígnicos.

No Brasil, destaca-se o estudo pioneiro de Júlio Plaza (2001, p.18), que entende a tradução como o processo intersemiótico por excelência, nos termos da semiose ilimitada de Charles Sanders Peirce. O mérito de Plaza foi o de instrumentalizar uma tipologia bastante pertinente para o exame dos processos tradutórios, mas tal classificação não se pretende estanque, pois sua preocupação é, sobretudo metodológica, como explica o autor (2001, p.89):

são tipos de referência, algumas vezes simultâneos em uma mesma tradução, que, por si mesmos, não substituem, mas apenas instrumentalizam o exame das traduções reais. Aliás, não estamos aqui senão atuando em correspondência com o mesmo espírito que guia a organização das tipologias de signos formuladas por Peirce.

Plaza define, portanto, três tipos de traduções intersemióticas: a) Tradução icônica ou transcriação. É regida pela semelhança de 
estrutura e os significados são produzidos sob a forma de qualidades da aparência. Tende a aumentar a taxa de informação estética, pois são mantidas similaridades materiais com o original, que visam despertar sensações análogas. b) Tradução indicial ou transposição. Pauta-se pela contiguidade (presença do original na tradução), mantendo uma relação ponto a ponto entre os elementos dos dois conjuntos. Determinada por uma relação de causa e efeito, valese das diferenças entre os meios e requer uma interpretação. c) Tradução simbólica ou transcodificação: utiliza-se de metáforas e símbolos em busca da contiguidade de referências convencionais, o que pressupõe um conhecimento prévio destas referências.

Para melhor entender a tipologia proposta, lembramos que, para Peirce (1975), existem três categorias de pensamento: a Primeiridade - ligada ao sensível ou qualitativo - e a Secundidade - ligada à experiência ou evento -, em oposição à Terceiridade ligada à razão. Tais categorias corresponderiam às três modalidades tradutórias de Plaza. È importante esclarecer que, como a semiose é um processo ininterrupto, o signo é múltiplo e variável, pois está sempre em diálogo com o signo que está sendo interpretado. Desse modo, seus poderes - evocativo (icônico), indicativo (indicial) ou significativo (simbólico) não são estanques - nenhum signo pertence apenas a um tipo exclusivo. Em qualquer processo sígnico, o que ocorre é a predominância de um desses valores sobre os outros. Nas palavras de Lúcia Santaella (2001, p.53):

essas distinções não são excludentes, os tipos não se excluem uns aos outros, mas evidenciam as múltiplas dimensões que os signos apresentam. As categorias peirceanas são onipresentes o que significa que um mesmo signo pode exibir uma pluralidade de faces ao mesmo tempo. Nessa medida, as classificações devem funcionar como meios para iluminar essa pluralidade e não para fixar um signo dentro de uma distinção, em detrimento das outras.

O corolário é que as distinções metodológicas da semiótica, quando aplicadas ao estudo da tradução intersemiótica, são ditadas pelas exigências internas da análise, ou seja, dependem do contexto da atualização desses signos e do ponto de vista de observação escolhido. Dentre as inúmeras possibilidades tradutórias para a 
adaptação de narrativas gráficas para as telas, verificamos que na versão fílmica da obra de Moore, a opção privilegia recursos cinematográficos tradicionais, como efeito de "realismo narrativo", ou seja, do conceito do cinema como ilusão. Com apoio em Plaza, consideramos se tratar de uma tradução indicial ou transposição, que se vale das diferenças entre o meio impresso e o cinema.

Cumpre assinalar que Alan Moore considerou o filme tão "infiel" à sua GN que pediu para seu nome ser eliminado dos créditos $^{2}$; entretanto, preferimos não entender esta ação tradutória como totalmente desvinculada do texto de origem. Em princípio, julgamos que a "infidelidade" ao texto-fonte não pode ser tomada como fator de valoração; afinal, estão em cena dois sistemas semióticos distintos, em diferentes suportes: a página impressa e a tela. Mesmo que apenas parte do original seja aparentes no filme, consideramos que a exploração da noção de deslocamento metonímico é uma forma de manter o vínculo com o todo do texto-fonte, uma vez que o filme observa as relações de causa e efeito, bem como sua essência conceitual.

Plaza (2001, p.30) afirma ser natural e até mesmo desejável que ocorram modificações nas adaptações, uma vez que "[...] numa tradução intersemiótica, os signos empregados tem tendência de formar novos objetos imediatos, novos sentidos e novas estruturas que, pela sua própria característica diferencial, tendem a se desvincular do original".

\section{Das páginas para as telas}

A graphic novel de Alan Moore e David Lloyd é uma contundente alegoria política, cujo protagonista é um heroi às avessas, um terrorista mascarado, cujo objetivo é explodir o Parlamento Inglês e, dessa forma, colocar em prática discursos ideológicos que

\footnotetext{
${ }^{2}$ Sendo um dos autores responsáveis pela elevação das revistas em quadrinhos à condição de literatura, os principais trabalhos de Moore adaptados para o cinema foram: Do Inferno, A Liga Extraordinária, Constantine, $V$ de Vingança e Watchmen, muito embora ele tenha detestado todos os filmes e conseguido tirar seu nome dos créditos. Deixando de lado suas idiossincrasias, Moore é considerado um gênio, cuja obra subverte a realidade e o próprio conceito de pós-modernidade.
} 
funcionam como ataque frontal ao poder totalitário. "Lembraivos, lembrai-vos o 5 de novembro!" é a frase inicial da narrativa no cinema, numa alusão à "Conspiração da Pólvora" (1605) que pretendia assassinar o rei protestante Jaime I da Inglaterra e todos os membros do Parlamento. A máscara de $\mathrm{V}$ remete à imagem de Guy Fawkes, um soldado especialista em explosivos, responsável por guardar os barris de pólvora que seriam utilizados no atentado católico, que não teve êxito.

O interessante é que o contexto da obra original revela incríveis similaridades temáticas com a época da filmagem da adaptação, principalmente no que tange às ações de terroristas no contexto histórico atual. Isso motivou inúmeros questionamentos sobre a proposta de James Mc Teigue e dos irmãos Wachowski quando realizaram $V$ de Vingança. A estreia do filme causou polêmica, além da óbvia pergunta se o filme seria uma espécie de Matrix ressuscitado, por força dos efeitos especiais e das cenas de combate. Especulouse até mesmo sobre um improvável incentivo ao terrorismo islâmico devido às coincidências históricas que cercaram seu lançamento, muitas vezes adiado: os ataques terroristas ao metrô de Londres (21/07/2005) e às Torres Gêmeas, em Nova York (11/09/2007).

Como nosso foco é o processo tradutório efetuado, não pretendemos aprofundar o viés ideológico, muito menos uma perspectiva historicizante, porém, não podemos deixar de assinalar como esta transposição fílmica de uma narrativa gráfica de ficção acabou sendo investida, por forças sincrônicas de conjuntura histórica, de sentidos episódicos e datados. Objetivamente, o que se pode observar é uma coincidência de temas, já que a narrativa gráfica foi publicada entre 1988 e 1989, como uma crítica a regimes autoritários, com claras alusões ao fascismo e a qualquer tipo de tirania. A trama transcorre num futuro apocalíptico, tanto no original (1997) quanto no filme (2020) quando a Inglaterra estaria dominada por um governo neonazista. Mostra uma população robotizada, que aceita abrir mão da liberdade e viver sob rigoroso monitoramento, em um ambiente de policiamento ostensivo e vigilância eletrônica, em troca de segurança. Há alusões à política inglesa e aos EUA, pois a narrativa é uma metáfora dos símbolos 
do poder no século XX; mas a obra também pode ser vista como um "novo 1984", filme baseado no romance de George Orwell, com seu indefectível Big Brother. Nos dois filmes, os ditadores dão suas ordens e fazem as exigências mais descabidas aos seus subordinados e à população, por meio das enormes telas, nas quais seus rostos aparecem em destaque. As expressões ameaçadoras de ambos servem como traços suprassegmentais para sua falas autoritárias e ameaçadoras.

Cumpre assinalar também que a temática adulta da GN dá o tom fortemente político, erudito e intimista ao filme, bem distante de um mero longa-metragem de superherois.

\section{Mutatis mutandi}

Will Eisner (1999, p.5), quadrinista reverenciado e teórico das HQs, explica que arte sequencial caracteriza-se por ser “(...) uma forma artística e literária que lida com a disposição de figuras ou imagens e palavras para narrar uma história ou dramatizar uma idéia”. O autor usa o termo para designar as histórias em quadrinhos como gênero narrativo com imagens sequenciadas. Segundo ele, essas narrativas, quando vistas quadro a quadro, são apenas desenhos; porém, esses mesmos desenhos, quando colocados em sequência, formam uma narrativa. Eisner refere-se a uma "gramática" da Arte Sequencial e afirma que "[...] o texto é lido como uma imagem" (ibid.), lembrando que imagens e símbolos reconhecíveis, quando usados repetidas vezes para expressar idéias similares, tornam-se uma linguagem. O autor (1999, p.8) orienta a leitura de uma HQ em seus elementos constitutivos, como as imagens, o timing, o quadro, os balões, entre outros. Ele afirma que "[...] a leitura da revista em quadrinhos é um ato de percepção estética e de esforço intelectual”, já que o leitor precisa, para efetivamente ler o texto, exercer suas habilidades interpretativas, tanto visuais quanto verbais.

Em termos epistemológicos, estando organicamente inseridas na cultura de massas, as Histórias em Quadrinhos recriam as heranças mitológicas ancestrais sob a forma de uma constelação de "mitos modernos", ressignificando não só a eterna disputa entre o bem e o mal, mas também os estereótipos da heroicidade, em suas 
narrativas ficcionais. De acordo com Edgar Morin (1977, p.90): um gigantesco impulso do imaginário em direção ao real tende a propor mitos de auto-realização, heróis modelos, uma ideologia e receitas práticas para a vida privada. (...) E é porque a cultura de massa se torna o grande fornecedor dos mitos condutores do lazer, da felicidade, do amor, que nós podemos compreender o movimento que a impulsiona, não só do real para o imaginário, mas também do imaginário para o real.

As histórias em quadrinhos revelam processos mitificadores, com protagonistas nascidos em outros planetas ou mesmo na Terra, que desenvolvem superpoderes para salvar salvá-la da destruição, ou ainda que, por um desejo de vingança e de impedir/reparar as ações dos vilões, iniciam uma escalada de redenção e salvação. Este tipo de heroicidade, já bem conhecida desde os grande heróis mitológicos, tem sido desenvolvida pela literatura folhetinesca do século 19, pelo cinema épico ou de aventuras e pela televisão, servindo, enfim, a uma cultura industrial de massa.

$\mathrm{O}$ antiheroi de Alan Moore, no entanto, é um ser em conflito, que procura ajustar as contas com os que destruíram sua família e o transformaram em alguém obrigado a esconder o rosto e as mãos, profundamente deformados; um ser destinado à solidão e que cultiva utopias românticas e anarquistas em torno do ideal da liberdade.

Em uma abordagem comparatista não se deve confundir sequência de imagens fixas com seqüência fílmica. No primeiro caso, as sucessões espaçotemporais são reguladas por leis diferentes, porque o tipo de leitura da mensagem também será diferente. Os altos valores simbólicos das imagens estáticas que se sucedem correlacionam-se para dar um sentido completo ao todo.

Por outro lado, no espaço próprio da sequência fílmica, o que importa é sua dinâmica e seus componentes, uma vez que nossos olhos não são capazes de perceber, durante a projeção, os intervalos que separam os fotogramas na cópia do filme. O físico belga Joseph-Antoine Plateau foi o primeiro a medir o tempo da persistência retiniana, ao concluir que, para uma série de imagens darem a ilusão de movimento, é necessário que se sucedam à razão de dez por segundo. Atualmente, a velocidade da filmagem é de 24 fotogramas por segundo. Isto quer dizer que uma sucessão de 
figuras (imagens) passadas torna-se capaz de mostrar a sensação do movimento contínuo. A conhecida teoria de Plateau é fundamental para os estudos de cinema e também para as abordagens das obras da arte sequencial.

Tendo em vista dois sistemas semióticos diferentes, porém, organizados a partir de uma narrativa ficcional em comum, a ênfase de minha abordagem recai nas modalidades de organização das imagens e respectivos efeitos, com o objetivo de apontar detalhes significantes, percebidos na passagem do meio impresso para a tela. Na GN original, destaca-se o uso versátil das subdivisões em quadrinhos ou vinhetas, de acordo com a necessidade dramática de cada cena. A diagramação das páginas é bastante heterogênea e esta diversidade de disposição das vinhetas revela uma intencionalidade signifi-

Figura 1: Página da GN

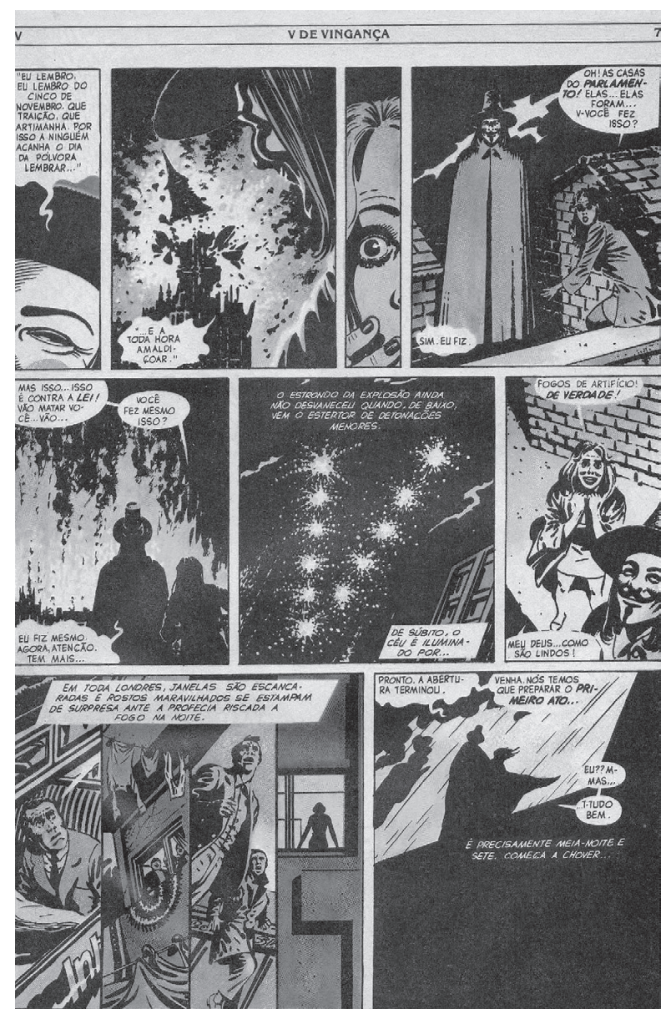

cativa. A disposição, a forma e o tamanho de cada vinheta revelam-se elementos estruturantes essenciais da ação, o que permite a percepção do timing de que fala Will Eisner (1999, p.26).

No cerne do uso sequencial de imagens com o intuito de expressar tempo está a comunidade da sua percepção. Mas, para expressar o timing, que é o uso dos elementos do tempo para obtenção de uma mensagem ou emoção específica, os quadrinhos tornam-se o elemento fundamental.

Uma vez disposto na sequência, o quadrinho torna-se o vetor da ilu- 


\section{Figura 2: Frame do filme ${ }^{1}$}

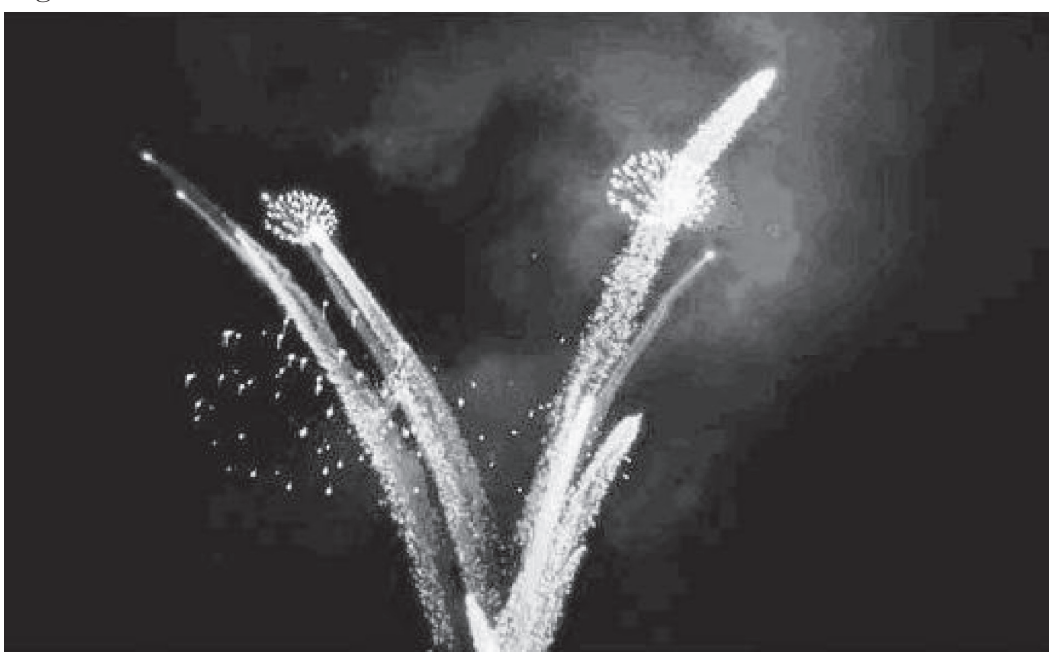

são de tempo, pois indica a duração de cada evento, como se vê na figura 1.

Vale notar que a vinheta central da página impressa mostra fogos de artifício, em forma de V, comemorando a destruição do Parlamento Inglês; cena esta que merece destaque no filme (figura 4.)

Por outro lado, o ritmo é completamente alterado quando uma vinheta toma toda uma página. Isso ocorre com frequência na GN analisada, em páginas sem nenhum signo verbal, nem mesmo numeração. Elas funcionariam como capas internas, contextualizando as ações. Na narrativa gráfica $V$ de Vingança exitem três tipos dessas "capas internas": o cenário urbano (com detalhes dos prédios, do metrô ou das ruas); o detalhamento de parte de uma cena (enfatizando as ações); e os closes do rosto de um personagem (com ênfase na emoção). Cada uma dessas páginas tem apenas uma única cor, sempre suave e o preto (verde-claro e preto, azul-claro e preto, lilás e preto etc.), o que demonstra a

\footnotetext{
${ }^{1}$ Todos os frames do filme foram capturados do DVD, pela autora do artigo.
} 
proposta gráfica peculiar que configura esta versão impressa como um sistema semiótico desviante em relação ao gênero.

O cenário urbano noturno assemelha-se às obras de Eisner e Miller, mas recebe um tratamento diferenciado. A primeira coisa que se observa é que não há onomatopéias, uma das marcas iconográficas específicas das HQs. Tal ausência poderia ser interpretada como um direcionamento a um público adulto e com um repertório mais sofisticado, o que parece ser previsto pelo uso de citações intertextuais eruditas.

Destacam-se também, na organização visual das páginas, os letreiros que anunciam os capítulos. Em sua maioria, os títulos são similares aos dos cinema mudo, sendo sobrepostos às vinhetas, com fundo negro e letras brancas. Como exceção, o capítulo quatro tem letras amarelas e seu nome é Vaudeville, gênero burlesco também conhecido como Teatro de Variedades, com origens do século 18, que fazia muito sucesso no final do século 19 e no início do século 20, com notável influência nos filmes da época e, até mesmo,

Figura 3: Cartaz de Vaudeville, 1899 (fonte: wikipedia. org)

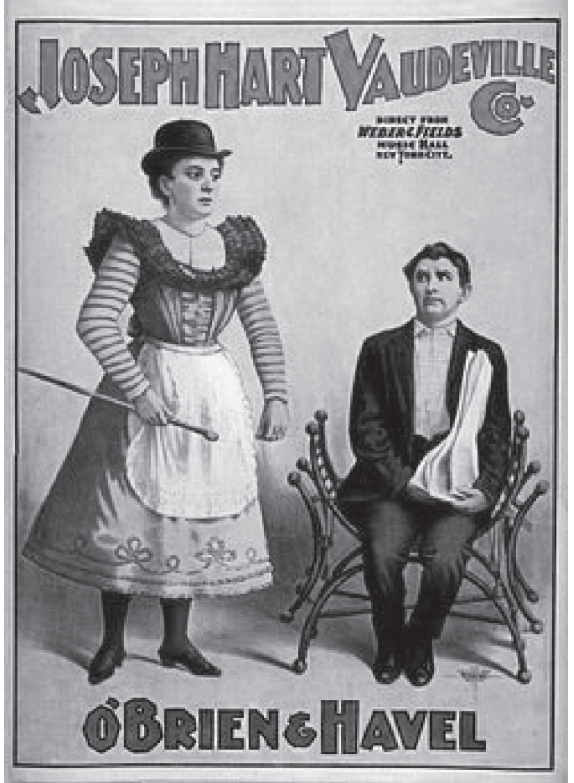
décadas após, nos famosos musicais hollywoodianos .

Tanto no cartaz quanto na página da GN (figura 4) pode ser observada a tonalidade amarelada em contraste com cores quentes e com o negro. Tal modalidade cromática sugeriria o idealismo romântico e antiquado de V, tanto em seus gestos e ações, quanto em seu gosto musical e literário. No filme, entre peças eruditas e clássicos do rock'n roll, ouvem-se canções da bossa nova, principalmente em raros momentos de relativa intimidade entre o protagonista mascarado e a jovem. 
Figura 4: metade de página da GN
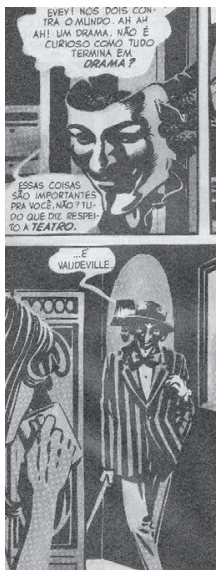
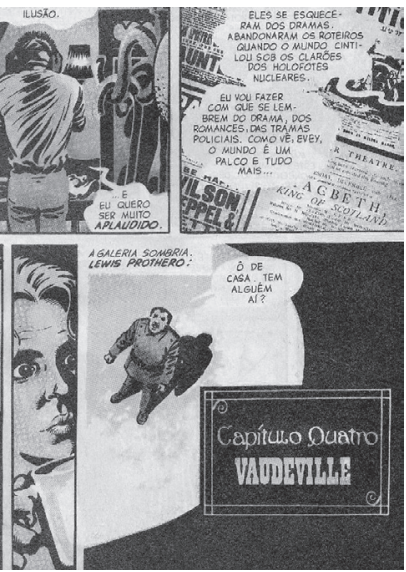

Deveras importante é a associação constante ao teatro de Vaudeville, que sempre se fazia acompanhar de música, tendo dado origem ao espetáculo de variedades com presença de números musicais, o que explicaria o papel da música na GN e o entendimento das ações do heroi vingador, principalmente porque ele toca piano em momentos cruciais para o desenvolvimento

da trama.

A narrativa é repleta de referências musicais e podem ser observadas várias páginas com uma única imagem que apresentam $\mathrm{V}$ ao piano, com suas mãos enluvadas ao teclado; sendo algumas vinhetas inteiramente tomadas pela imagem do instrumento.

Figura 5: Duas páginas inteiras da GN
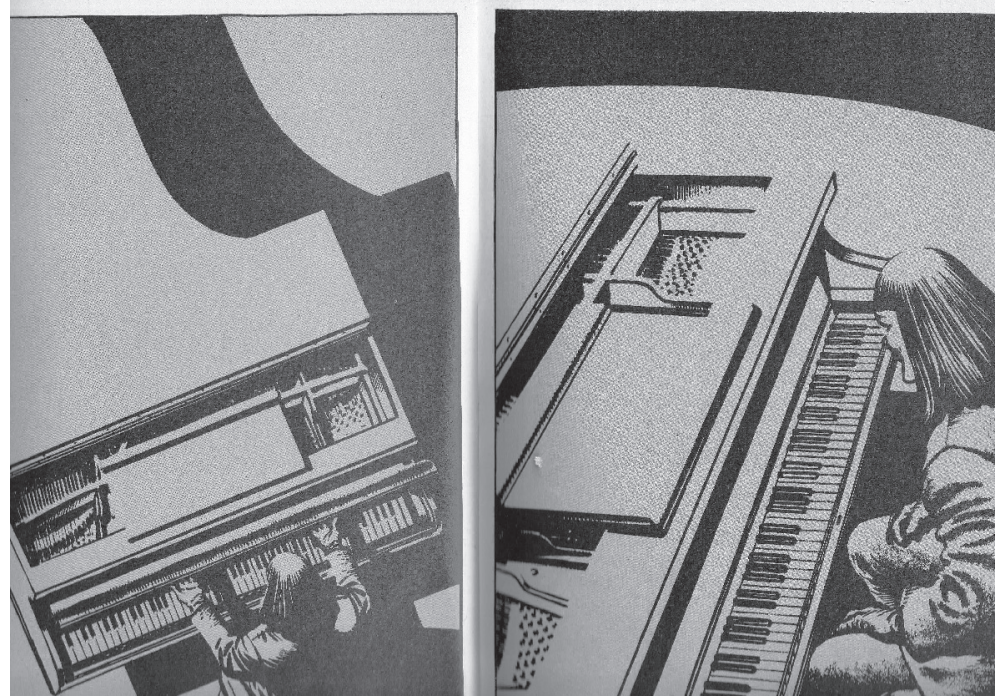
Faz-se necessário destacar que, desde o fim do século 19, uma modalidade expressiva da execução pianística faria perdurar o estilo romântico de interpretação. Muitos pianistas se destacariam com um estilo próprio e marcante, traduzindo em sonoridade, nuances e colorido a expressão de suas personalidades. Este é mais um elemento da caracterização do protagonista. As duas imagens gráficas, abaixo, apresentam enquadramentos cinematográficos e exploram o simbolismo da cor azulada.

Nas páginas seguintes, a alusão à música fica ostensiva e bastante original, em se tratando de uma GN, principalmente entre as páginas 30 e 41, que são constituídas como uma sequência ilustrada musicalmente. Como um longo travelling horizontal, passa-se de uma página a outra, com o mesmo esquema cromático e a mesma diagramação, em que as vinhetas são alternadas com linhas de partituras musicais. Esta é a única parte da GN que tem diagramação uniforme e na horizontal: são vinhetas estreitas, em duplas e delimitadas pelas linhas da partitura musical. Com Eisner, diríamos que o timing é conservado durante toda a seqüência. $O$ efeito é extraordinário para uma narrativa gráfica, como se observa

Figura 6: Página horizontal da GN

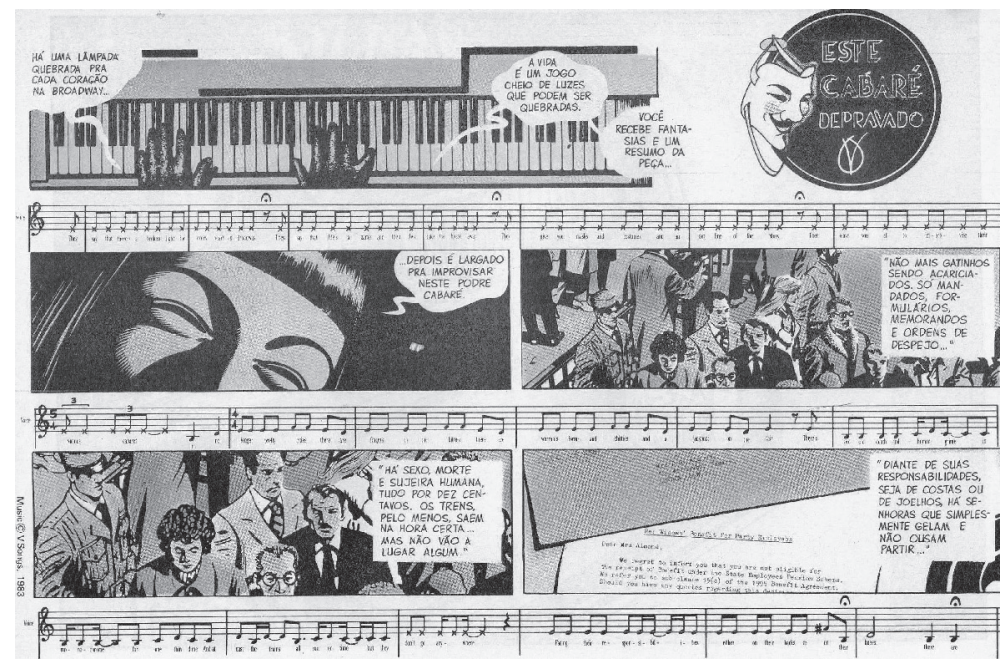


na página abaixo, que tem no canto superior esquerdo um balão, com a fala de V: "Há uma lâmpada quebrada para cada coração na Broadway". Do lado direito, em relação visual de equilíbrio, aparece um círculo negro, com a máscara de $\mathrm{V}$ pendurada e a inscrição: "Este cabaré depravado". A inscrição em si, metaforiza a visão do protagonista sobre os ambientes nos quais se vê obrigado a circular.

Para Eisner, tanto o código Morse quanto uma passagem musical podem ser comparados a uma tira de quadrinhos, já que incluem o uso do tempo na sua expressão. $\mathrm{O}$ autor pontua que as linhas desenhadas em torno da representação de uma cena, como dispositivo de contenção da ação, podem se integrar ao enunciado total, tornando-se partes do vocabulário iconográfico utilizado para o delineamento temporal da narrativa.

No caso da página analisada, as linhas da partitura são significantes, porque iconizam a trilha sonora e impõem um ritmo especial às ações.

Outro aspecto relevante a destacar é o estilo repleto de intertextualidades da graphic novel - versos de Shakespeare, o romance de capa e espada de Alexandre Dumas, o livro de George Orwell, quadros surrealistas de Max Ernst, a música de Tchaikovski, Rolling Stones e Sex Pistols, o teatro burlesco do Vaudeville, quadrinhos de Judge Dredd, entre outras citações. Muitas delas estão presentes na adaptação, no entanto - talvez devido ao tempo estimado para a projeção de um filme - não seja possível contemplar toda a riqueza do dialogismo polifônico criado por Moore, que constrói, por meio da bricolagem, um futuro distópico, além de sombrio e totalitário.

\section{Negociações tecnoestéticas: constrastes e similaridades}

Nas negociações tecnoestéticas efetuadas para a transposição fílmica, a primeira diferença que se sobressai é a eliminação de muitos personagens dos quadrinhos, pois os roteiristas concentraram a narrativa em apenas três deles: o terrorista da máscara sorridente V e o investigador que o persegue, Finch; além da garota Evey, que o heroi salva e com quem se envolve platonicamente. 
Mesmo esse trio foi consideravalmente modificado. Nas revistas originais, Evey é menor de idade e trabalha como prostituta; no filme ela é mais velha, menos ingênua e produtora de TV. Não parece haver nenhuma conotação erótica a uni-los, apesar de ambos serem movidos por ideais libertários e pela sede de vingança, pois Evey, quando criança, viu seus pais serem assassinados pelo regime.

Nos gibis, Sutler, o primeiro-ministro totalitário da Grã-Bretanha, é um quarto personagem importante, enquanto no filme ele só aparece brevemente, na TV. Dentre aspectos ideológicos

Figura 7: Vinheta da HQ

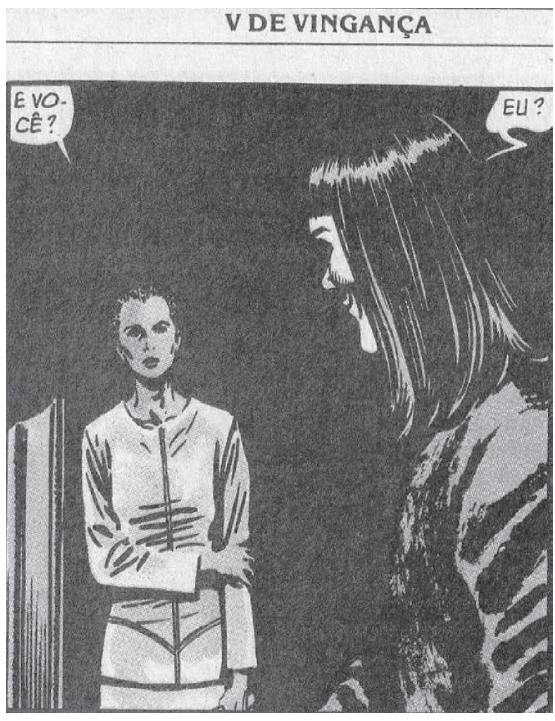

Fig. 8: Frame do filme

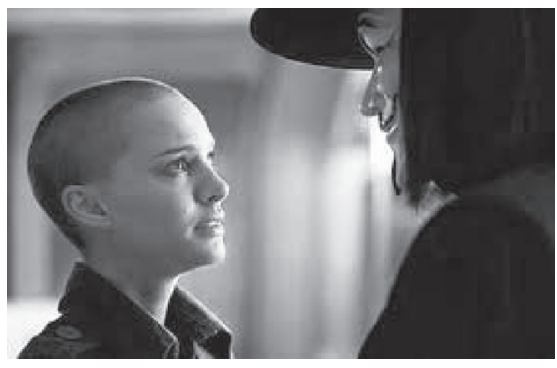

essenciais do texto de Alan Moore, destacam-se a tese de que é possível um anarquismo utópico e o romantismo idealizado, ambos ligeiramente diminuídos, mas não eliminados pelas modificações efetuadas no filme.

O filme apresenta inúmeras cenas praticamente idênticas às vinhetas originais, manifestando a tentativa de manutenção de uma relação ponto a ponto com os elementos do texto-fonte. Contudo, sua estrutura narrativa não é determinada pelos signos antecedentes, mas sim por uma relação de causa e efeito, valendo-se das diferenças entre os meios. Apresentamos abaixo quatro vinhetas e as cenas correspondentes, para que possam ser cotejadas.

$\mathrm{O}$ fato de $\mathrm{V}$ invadir uma emissora de televisão e usar "A Voz do Destino" - o telejor- 


\section{REFLEXÕES SOBRE A ADAPTAÇÃO COMO FENÔMENO UBÍQUO}

nal que é um veículo do governo acompanhado por todos -, demonstra como a relação com a imprensa é determinante no que se refere à consciência política da população; não é por acaso que surgiu o conceito de "quarto poder". A esta ação do protagonista é dedicada uma imagem de página inteira, que poderia significar a relevância de se lutar com as mesmas armas do inimigo. No filme,

Figura 9: Imagem de página inteira

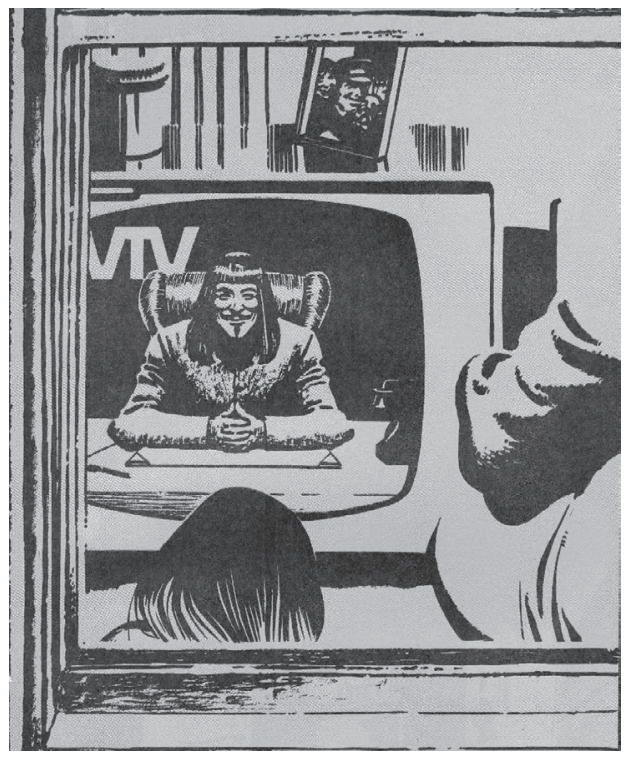

Figura 10: Frame do filme

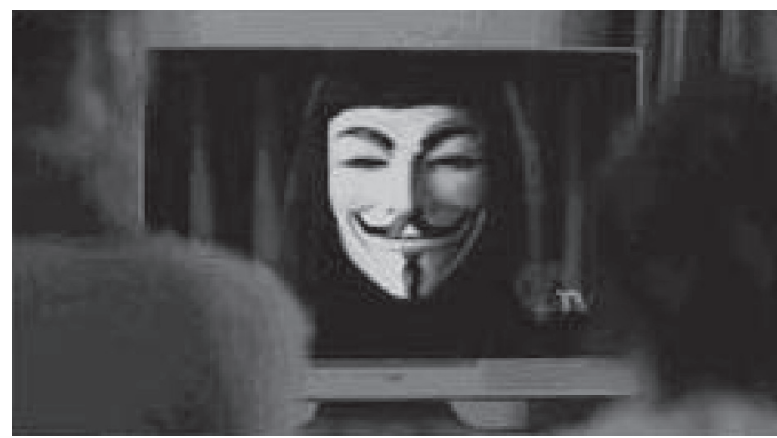


a imagem da televisão ocupa a tela toda. Pode-se perceber uma crítica ao controle das mídias, tanto pelos governantes quanto pela imprensa em geral. É neste momento que V reaparece e convoca seus compatriotas a erguerem-se contra a tirania e opressão do

Figura 11: Vinheta da GN

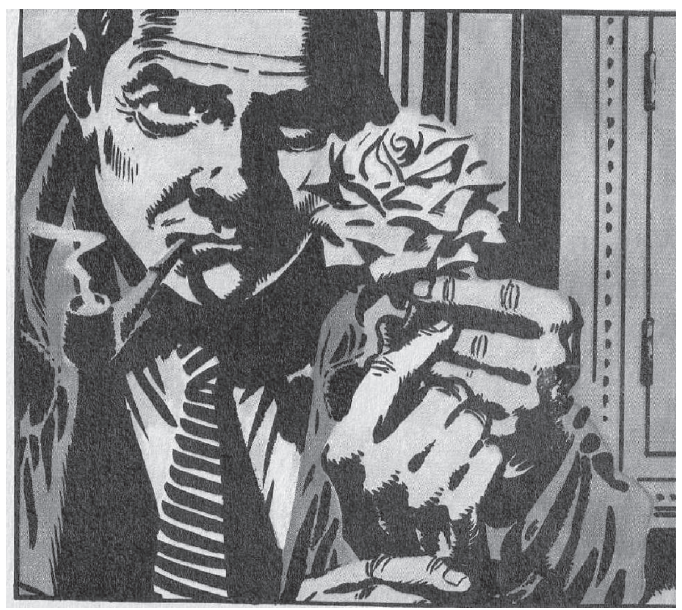

Figura 12: Frame do filme

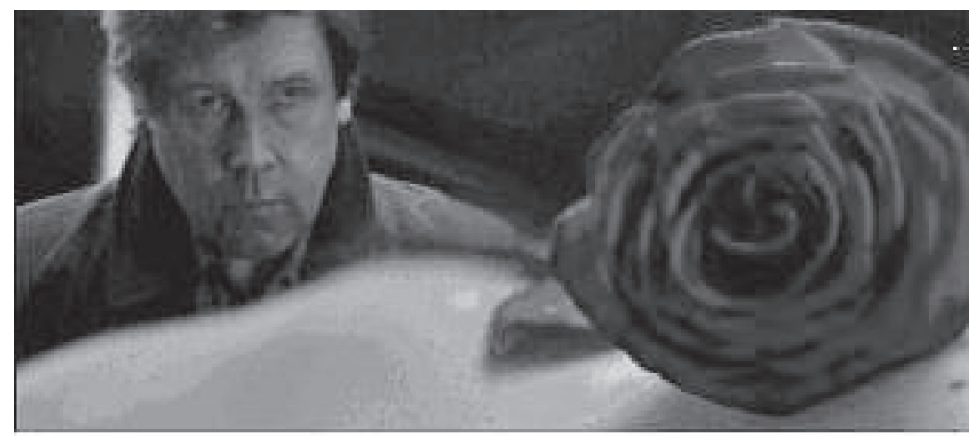

insano Sutler, com seu supercomputador, que permite ao estado vigiar todas as ações dos cidadãos.

Outro elemento relevante é a ênfase dada ao amor de V às rosas raríssimas que ele cultiva e que poderiam estar apenas acentuando o romantismo do sofisticado protagonista. Entretanto, 
ele se utiliza delas para deixar seu "recado" junto aos corpos das vítimas de sua vingança.

Na cena que mostra o detetive encontrando a rosa ao lado de um cadáver, conserva-se uma grande semelhança entre as duas imagens.

Sendo flores altamente simbólicas, as rosas agregam diferentes significados e conotações, dependendo de cada cultura. Tomando como exemplo a rosácea gótica e a rosa-dos-ventos, que marcam a passagem do simbolismo da rosa ao da roda do tempo, poderíamos estabelecer uma associação com o dito popular: "Aqui se faz aqui se paga" - o que explicaria a ligação paradoxal da flor com os atos vingativos do protagonista $\mathrm{V}$.

\section{Ponderações finais}

Qualquer abordagem das textualidades midiáticas contemporâneas deve levar em conta que estamos diante de um novo tipo de texto, de caráter híbrido, que exige uma abordagem inter e transdisciplinar. Conceitos e classificações pragmáticas mais recentes procuram incluir, além das relações entre textos verbais e visuais, as outras relações intersemióticas. Mesmo tais estudos ainda não abarcam toda a complexidade de textos multimidiáticos, nos quais se encontram simultaneamente signos de diferentes sistemas ou códigos.

Obviamente que aferições de valor, como "o original é melhor que o filme", são subjetivas o bastante para não merecerem respaldo crítico. Roland Barthes trata da questão ao afirmar que texto, filme e vida são "espaços fluidos, porosos e permeáveis", ou seja, são territórios intertextuais, uma rede de textos verbais ou não, que se incorporam a este "grande emaranhado que é uma obra, seja ela literária ou cinematográfica.” Para o autor (2004, p.63), sendo um espaço de dimensões múltiplas "O texto é um tecido de citações, oriundas dos mil focos da cultura."

Tendo em vista o contexto atual, no qual se observa uma indústria dos quadrinhos expandida e múltipla, o que torna ainda mais complexo o mapeamento de seus subgêneros, acreditamos que o processo tradutório da obra $V$ de Vingança conseguiu efetivar-se como uma adaptação fílmica bem sucedida. A conclusão deste 
artigo caminha para afirmar que a obra cinematográfica analisada conseguiu contemplar adequadamente as especificidades e sutilezas intermidiáticas do texto-fonte, pois foi mantido o tom fortemente político, erudito e intimista da narrativa de Alan Moore.

De modo diverso ao final da narrativa gráfica, o filme termina com as pessoas usando máscaras iguais à de $V$ e servindo de platéia para a última ação do vingador. Esta imagem reforça o conceito clássico do theatrum mundi, que equacionou a sociedade com o teatro e a ação cotidiana com a atuação, idéia que é reiterada nas falas do protagonista da narrativa de Moore; o conceito remete a outras possibilidades interpretativas da obra e aponta para a continuidade deste estudo, à luz de categorias e molduras teóricas adequadas.

\section{REFERÊNCIAS}

ARBEX, Márcia. (org). Poéticas do visível - ensaios sobre a escrita e a imagem. Belo Horizonte: Editora da UFMG, 2006.

BARTHES, Roland. O rumor da língua. São Paulo: Martins Fontes, 2004.

CLÜVER,Claus. Estudos interartes. Conceitos, termos, objetivos. In: LITERATURA E SOCIEDADE. São Paulo: Ed.USP, no. 2. 1997. p. 37-55.

ECO, Umberto. Apocalípticos e Integrados. São Paulo: Perspectiva, 1976.

. Quase a mesma coisa. Rio de Janeiro: Record, 2007.

EISNER, Will. Quadrinhos e Arte Seqüencial. São Paulo: Martins Fontes, 1999.

GENETTE, Gérard. Palimpsestes. La littérature au second degré. Paris: Seuil, 1982.

HUTCHEON, Linda. A theory of adaptation. Nova Iorque e Londres: Routledge, 2006.

MCLOUD, Scott. Understanding Comics. Nova York: Kitchen Sink, 1993.

MOORE, Alan; LLOYD, David. V de Vingança. Minissérie completa. São Paulo: Editora Globo, 1990. 


\section{REFLEXÕES SOBRE A ADAPTAÇÃO COMO FENÔMENO UBÍQUO}

MORIN, Edgar. Cultura de massas no século XX: o espírito do tempo. Rio de Janeiro: Forense-Universitária, 1977.

NAREMORE, James. (org). Film adaptation. London: The Athlone Press, 2000.

ORWELL, George. 1984. São Paulo: Editora Nacional, 1996.

PEIRCE, Charles Sanders. Semiótica e Filosofia. São Paulo: Cultrix, 1975. PLAZA, Julio. Tradução intersemiótica. São Paulo: Perspectiva, 2001.

SANTAELLA, Lúcia. Matrizes da linguagem e pensamento: sonora visual verbal. São Paulo: Iluminuras, 2001.

STAM, Robert. A literatura através do cinema. Realismo, magia e a arte da adaptação. Belo Horizonte: Editora UFMG, 2008.

Recebido em: 05/07/2010

Aceito em: 19/02/2011 